\title{
PROGRESSO E BARBÁRIE
}

\section{Delcio Junkes 78}

\section{Resumo}

Este artigo pretende apresentar algumas reflexões a partir do conceito de progresso e como ele pode se converter em totalitarismo. Para tanto, tomo como base teórica o pensamento de Theodor Adorno acerca desta questão e, em especial, a influência exercida por Walter Benjamin quando estabelece uma relação inseparável entre progresso e barbárie, ao mesmo tempo em que o associa à imagem de redenção, com a promessa de uma felicidade futura que supere a catástrofe do presente. A noção de progresso que será defendida parte do pressuposto iluminista de que o progresso da sociedade e humanidade não podem ser pensados de modo separado.

Palavras chave: Progresso, barbárie, humanismo, redenção, história.

\begin{abstract}
This article intends to present some reflections from the concept of progress and how it can become totalitarianism. To that end, I take as a theoretical basis Theodor Adorno's thinking on this issue and in particular, influenced by Walter Benjamin when he establishes an inseparable relationship between progress and barbarism, at the same time as associating him with the image of redemption, with the promise of happiness future that overcomes the catastrophe of the present. The notion of progress that will be defended starts from the Enlightenment assumption that the progress of society and humanity can not be thought of separately.
\end{abstract}

Key words: Progress, barbarism, humanism, redemption, history.

\section{Nunca houve um monumento da cultura que não} fosse também um monumento da barbárie.

Benjamin

No aforismo Frutas anãs da Minima moralia Adorno faz uma série de afirmações categóricas que se resumem na maioria dos casos a apenas uma frase, mas que expressam a radicalidade de suas posições. A que nos interessa aqui é uma reformulação da sentença de Hegel "o verdadeiro é o todo", que é reescrita como "o todo é o não verdadeiro" (ADORNO, 1993, p. 42), e parece comportar o caráter que o progresso adquiriu a partir do uso unilateral da razão. Para ilustrar essa ideia de totalidade enquanto afirmação do não verdadeiro, inicio com um trecho um pouco longo de Notas de inverno sobre impressões do verão, um escrito de Dostoievski, no qual ele relata de forma quase jornalística, mas com boas doses de sua ironia

\footnotetext{
${ }^{78}$ Professor Doutor (UFPR). Membro do Nesef UFPR.E mail: delciojunkes@hotmail.com
} 
socrática, a viajem que fez pela Alemanha, Inglaterra e França. Esta ocorreu possivelmente em 1862, já que ele se refere nessa passagem à Exposição Internacional que ocorreu nesse ano em Londres e que tinha por finalidade apresentar ao grande público progresso técnico da indústria até então.

A City, com seus milhões e o seu comércio mundial, o Palácio de Cristal, a Exposição Internacional... Sim, a exposição é impressionante. Sente-se uma força terrível, que uniu num só rebanho todos estes homens inumeráveis, vindos do mundo inteiro; tem-se consciência de um pensamento titânico; sente-se que algo já foi alcançado aí, que há nisso uma vitória, triunfo. Até se começa como que a temer algo. Por mais que se seja independente, isto por alguma razão nos assusta. "Não será este realmente o ideal atingido?", pensase. "Não será, este de fato, o 'rebanho único'?" Não será preciso considerá-lo como a verdade absoluta, e calar para sempre? Tudo isso é tão solene, triunfante, altivo, que nos oprime o espírito. Olham-se estas centenas de milhares, estes milhões de pessoas que acorrem docilmente para cá de todo o globo terrestre, pessoas que vieram com um pensamento único, que se aglomeram plácida, obstinada e silenciosamente neste palácio colossal, e sente-se que aqui se realizou algo definitivo, que assim chegou ao término. Isto constitui não sei que cena bíblica, algo sobre a Babilônia, uma profecia do Apocalipse que se realiza aos nossos olhos. Sente-se a necessidade de muita resistência espiritual e muita negação para não ceder, não se submeter à impressão, não aceitar o existente como sendo o ideal... (DOSTOIÉVISKI, 2000, p. 114-115).

Uma ideia bastante comum na sociedade contemporânea, e que muitas vezes aparece como crença ou esperança, é a ideia de que só o progresso pode libertar a humanidade de situações indignas, que limitam ou eliminam as suas possibilidades de realização dos ideais individuais e coletivos, sejam elas causadas por catástrofes naturais ou pelo abuso do poder, da força e da violência, ou seja, da barbárie produzida pelo próprio ser humano. Segundo essa mesma crença, se ainda não atingimos um estágio que se possa considerar como uma sociedade ideal, de acordo com Adorno, 'onde haja equivalência entre justiça e liberdade', onde a humanidade tenha se libertado de toda injustiça e miséria, onde a felicidade torne-se uma possibilidade concreta para todo ser humano, é porque ainda não progredimos o suficiente, pois, junto com a ideia de progresso sempre esteve presente a inevitável crença na redenção, a "esperança de que finalmente as coisas melhorem, de que, enfim, as pessoas possam tomar alento" (ADORNO, 1995, p. 39). Como em Benjamin, quando descreve em Experiência e pobreza, a volta dos soldados da Primeira Guerra, segundo ele uma das mais terríveis experiências da história. Depois da experiência da guerra soldados voltaram vazios e incomunicáveis do campo de batalha atestando a fragilidade do ser humano diante do avanço 
da técnica.

Uma nova forma de miséria surgiu com esse monstruoso avanço da técnica, sobrepondo-se ao homem. (...) A terrível mixórdia de estilos e concepções do mundo do século passado mostrou-nos com tanta clareza onde esses valores culturais podem nos conduzir, quando a experiência nos é subtraída, hipócrita e sorrateiramente, que é hoje em dia uma prova de honradez confessar nossa pobreza. Sim, é preferível confessar que essa pobreza de experiência não é mais privada, mas de toda a humanidade. Surge assim uma nova barbárie. Barbárie? Sim. Respondemos afirmativamente para introduzir um conceito novo e positivo de barbárie. Pois o que resulta para o bárbaro dessa pobreza de experiência? Ela o impele a partir para a frente, a começar de novo, a contentar-se com pouco, a construir com pouco, sem olhar para a direita nem para a esquerda (BENJAMIM, 1993, p. 115-116).

Essa passagem de Benjamin já antecipa o teor das suas teses Sobre o conceito de história, que vão influenciar as reflexões de Adorno sobre história e sobre o progresso, as quais serão abordadas mais adiante. Uma das questões fundamentais no pensamento de Adorno que já aparece no ensaio sobre o antissemitismo da "Dialética do Esclarecimento", mas que vai ser bastante aprofundada nas suas obras posteriores é: Como a filosofia pode contribuir para evitar a catástrofe? Como se pode conceber a educação após Auschwitz? Como afirma Adorno em Minima moralia: "Progresso e barbárie estão hoje, como cultura de massa, tão enredados que só uma ascese bárbara contra esta última e contra o progresso dos meios seria capaz de produzir de novo a não barbárie” (ADORNO, 1995, p. 39). Depois das grandes catástrofes do século XX é impossível pensar no progresso sem que com ele venha a imagem da decadência, sem que represente a anulação completa do indivíduo como previa a antiutopia de Huxley.

Adorno considera que quem busca precisar demasiadamente o conceito - no caso o conceito do progresso - corre o risco de acabar esquecendo ou destruindo o seu alvo, e como qualquer outro conceito filosófico, o conceito de progresso pode gerar equívoco.

A argúcia subalterna, que se recusa a falar de progresso antes que possa distinguir progresso do que, para que, em relação a que, desloca a unidade dos momentos que atuam entrelaçados em uma mera justaposição (ADORNO, 1993, p. 37).

No seu uso mais comum e às vezes até ingênuo, o progresso aparece como uma promessa que remete a algo que não se sabe definir propriamente o que seja, como resposta às dúvidas, como a felicidade absoluta, ou simplesmente como a esperança de que as coisas possam melhorar. Nesse sentido, não se pode dizer de modo preciso o que é o progresso. Mas 
quando se faz uma reflexão, que mesmo estando mergulhada no progresso mantém dele a distância necessária para não ser contaminado pela experiência individual e pelos significados especializados, existe a possibilidade de se conseguir uma reflexão verdadeira. Tais reflexões, para Adorno, culminam inevitavelmente na questão: a humanidade será capaz de evitar a catástrofe?

Exclusivamente sobre isso recai a possibilidade de progresso, a possibilidade de afastar a catástrofe extrema, total. Nisso deveriam cristalizar-se todos os problemas relativos ao progresso. A penúria material que durante muito tempo pareceu zombar do progresso está potencialmente afastada: tendo-se em conta o nível alcançado pelas forças produtivas técnicas, ninguém deveria padecer fome sobre a face da terra. Que continuem ou não a escassez e a opressão - ambas são a mesma coisa - dependerá exclusivamente de que se evite a catástrofe mediante a organização racional da sociedade total, como humanidade (ADORNO, 1995, p. 47).

É um equívoco entender o progresso somente como a fórmula publicitária do "sempre melhor", do aperfeiçoamento das técnicas de produção. Adorno recorre a Benjamin para afirmar que não é possível admitir a ideia de progresso sem a ideia de humanidade. Nas teses Sobre o conceito de história Benjamin considera que esse foi o erro dos socialdemocratas, que confundiram o progresso das habilidades e conhecimentos com o progresso da humanidade. Para Benjamin não se pode pensar o progresso da humanidade como se ela já existisse enquanto tal e assim pudesse progredir. Associada à ideia de progresso está a de felicidade para as gerações futuras, ou seja, o progresso implica inevitavelmente em redenção. A humanidade existente que se insinua para aquela que ainda não nasceu. De acordo com a tradição, o conceito de progresso é em parte filosófico e em parte social, sem a sociedade ele seria vazio de significado. Dessa forma, a sociedade progrediu da coleta e da caça para a agricultura, da escravidão para a liberdade formal dos indivíduos. No entanto, o conceito de progresso não se esgota na sociedade, não é idêntico a ela, podendo às vezes até ser oposto, porque no mesmo momento em que articula o movimento social ele quer uma confrontação com a natureza, o que faz com que se transforme em dominação.

O progresso que se manifesta de modo mais imediato no controle da natureza externa ao homem, carrega consigo uma contradição: ao mesmo tempo em que é esclarecimento, emancipação da consciência e possibilidade de transformação da realidade, ele é também o ofuscamento, o perigo de que se atinja uma totalidade em que não haja mais espaço para o diferente. É a tensão entre o individual e o total:

Se a imagem da humanidade em seu progresso evoca a de um gigante 
que - após um sono imemorial - lentamente se pusesse em movimento para, depois, desembestar e pisotear tudo o que surgisse em seu caminho, ainda assim seu despertar é o único potencial de emancipação, que o constrangimento à natureza, no qual o próprio progresso se enreda, não tenha a última palavra (ADORNO, 1995, p. 47).

O progresso é a ideia capaz de quebrar o círculo do sempre-idêntico, por ser gerado por esse mesmo sempre-idêntico pode acontecer a qualquer momento. Ele representa a tomada de consciência, o desencantamento da natureza que põe fim ao domínio da natureza e por meio do qual a natureza se prolonga. O progresso é dialético, pois cada momento se transforma em seu oposto. O progressivo domínio da natureza requer o desenvolvimento de uma razão a partir desse mesmo domínio. Essa razão que surgiu do princípio de dominação é a única que depois de transportada para o sujeito produz a possibilidade de supressão da dominação. Pela negação da dominação se libera a razão emancipadora "cada momento só se transforma em seu oposto ao, literalmente, refletir-se, quando a razão aplica a si mesma a razão, e, nessa autolimitação, emancipa-se do demônio da identidade" (ADORNO, 1995, p. $50)$.

A ideia de que o progresso total só surge como negação do progresso tem sua origem no princípio constitutivo da sociedade burguesa: a troca. Ela é o mito que desmistifica o próprio mito. O sacrifício realizado para aplacar a ira dos deuses ou para agradecer as dádivas recebidas, como forma de reconciliação com a natureza é substituído pela troca de equivalentes, do igual pelo igual, onde um ato compensa o outro, e no final o saldo se reduz a zero. Se a troca foi justa, tudo fica como antes, e o progresso não ocorreu. "Mas, ao mesmo tempo, a afirmação do progresso antagônica em relação aquele princípio - é tão verdadeira quanto é mentira a doutrina da troca de equivalentes" (ADORNO, 1995, p. 59). Ou seja, a troca é injusta. Nas relações capitalistas de produção o mais poderoso sempre recebe mais do que o outro, e essa injustiça é que torna o processo dinâmico; se a troca fosse verdadeiramente de equivalentes ela desapareceria, pois a troca vive do acréscimo. $\mathrm{O}$ acréscimo baseado na mentira da igualdade perpetua a injustiça e a desigualdade, às quais o progresso deveria abolir. No entanto, é essa mesma a condição que cria a possibilidade de justiça. Para o Zaratustra de Nietzsche, o homem deveria se redimir pela vingança, pois ela é o arquétipo mítico da troca. Pela vingança encontra-se um reparo ao dano sofrido; infringir dor ou sofrimento ao criminoso representa uma compensação para a injustiça. Enquanto existir a dominação pela troca, também o mito irá dominar. O progresso é então a resistência ao perigo da recaída no domínio do mito. 
O progresso se afirma como a confiança na capacidade de a humanidade combater o esquecimento pelo pensamento crítico, é a utilização da autorreflexão como alternativa ao totalitarismo, onde a emancipação, a utopia, a possibilidade do não idêntico possam ser admitidos. Adorno defende que o progresso tem de produzir um pensamento austero que resista à realidade e que faça a crítica constante de si mesmo, percebendo suas limitações e suas potencialidades, e que seja capaz de evitar a catástrofe e a barbárie.

No balanço do progresso, no processo de desencantamento do mundo, onde só é considerado esclarecido de fato aquilo que pode ser objetivado, e que o que realmente importa é o procedimento eficaz, a arte foi condenada à impotência. Classificada como ineficaz, ela assume o papel que a magia tinha no mito, ou seja, uma expressão sem consequências práticas, uma mera forma sem poder de ação. Para o esclarecimento a arte, assim como as figuras míticas, pode ser reduzida a um denominador comum, a saber, o sujeito. Mas, “de antemão ele só reconhece como ser e acontecer o que se deixa captar pela unidade. Seu ideal é o sistema do qual se pode deduzir toda e cada coisa" (ADORNO E HORKHEIMER, 1985, p.22), sua racionalidade é a equivalência, uma equação a partir da qual se possa calcular tanto a justiça quanto a troca mercantil, o que vem a ser a mesma coisa.

No cálculo da equivalência, no qual o diferente é comparável, o que não pode ser reduzido a números, a uma unidade conceitual, não passa de ilusão. No mundo do conceito no qual a unidade é definida como aquilo que já está nele subsumido, algo só é tornando-se o que não é. Essa dialética da separação entre a coisa e o conceito, que já estava presente no mito e que é intensificada na ciência, mantém sua impotência na medida em que a linguagem transforma-se em repetição, em tautologia. No mito havia a identificação do animado ao inanimado - o antropomorfismo sempre foi uma forma de entender e, consequentemente, tentar dominar a natureza -, já no esclarecimento há identificação do inanimado ao animado, da coisa ao conceito.

Quando algo deixa de ser o que é e passa a ser a representação do "mana", a saber, "daquilo que transcende o âmbito da experiência, aquilo que nas coisas é mais que sua realidade já conhecida" (ADORNO E HORKHEIMER, 1985, p.28-29), já se inicia a separação entre sujeito e objeto. Na sociedade capitalista isso aparece como fetiche, a linguagem exprime a contradição daquilo que é idêntico e não idêntico. No mundo esclarecido, o conceito e a técnica assumem o lugar que no mito era reservado ao ritual e ao sacrifício, a repetição de uma "fórmula mágica" capaz de restabelecer o equilíbrio entre a ação humana e ordem natural ou divina; seu objetivo é a redenção, a expiação da culpa por ter sido sujeito. Assim como o ritual no mito, o esclarecimento precisa da repetição do 
procedimento eficaz, da técnica, da equação onde tudo é igualado. "O preço que se paga pela identidade de tudo com tudo é o fato que nada, ao mesmo tempo, pode ser idêntico consigo mesmo" (ADORNO E HORKHEIMER, 1985, p.27).

O esclarecimento enquanto progresso do pensamento sempre teve por objetivo acabar com o medo e colocar o homem em uma posição de controle de si mesmo e da natureza, para que a esperança de um mundo justo e que as coisas finalmente melhorem então se possa realizar. Porém o que o progresso produziu efetivamente foi a possibilidade da catástrofe, e consequentemente a preocupação se ela poderá ou não ser evitada. A preocupação atinge o nível do desespero quando as próprias forças que produziram esse perigo o perpetuam para se conservarem. Se outrora o progresso aparecia como a promessa de dias melhores, como redenção do sofrimento, tanto na religião quanto no iluminismo representando a tão esperada libertação, no esclarecimento ele se confunde com a autopreservação. Como afirma Horkheimer em Eclipse da razão: "o tema deste tempo é a autopreservação, embora não exista mais um eu a ser preservado" (HORKHEIMER, 1976, p. 139). Na era da livre iniciativa e livre mercado a razão individual tornou-se um ego encolhido, incapaz de transpor sua posição da realidade. $\mathrm{O}$ indivíduo é apenas a síntese de seus interesses materiais, que a princípio não se identificam com o coletivo, mas que mesmo assim ainda acredita que a sociedade só avança por meio da competição irrestrita e o progresso é o resultado automático da interação de interesses divergentes.

Walter Benjamin afirma na oitava das suas Teses sobre o conceito de história, que a condição em que vivemos e o assombro que nos causam fatos que não compreendemos como ainda é possível que aconteçam no século XX (ou XIX), e que somos levados pelo conformismo a aceitar como sendo um 'estado de exceção', como acidentes na marcha do progresso que não desviam do fim que é sempre o melhor para a humanidade, na verdade constitui a regra geral. É necessário então que a partir dessa condição se busque construir um novo conceito de história.

A tradição dos oprimidos nos ensina que o "estado de exceção" em que vivemos é na verdade a regra geral. Precisamos construir um conceito de história que corresponda a essa verdade. Nesse momento, percebemos que nossa tarefa é originar um verdadeiro estado de exceção; com isso, nossa posição ficará mais forte contra o fascismo. Este se beneficia da circunstância de que seus adversários o enfrentam em nome do progresso, considerado como uma norma histórica (BENJAMIN, 1989, P.226).

Essa ideia aparece de modo semelhante no ensaio Razão e revelação, de Adorno, 
quando afirma que: "Como a instauração de uma ordem justa parece ser impossível aos homens, recomenda-se-lhes a existente e injusta" (ADORNO, 1995, p.31). O que demonstra que, tanto na visão de Benjamin quanto de Adorno, existe um sentimento de derrotismo da humanidade que parece não mais acreditar na possibilidade de que o progresso possa levar a um desenvolvimento do indivíduo e a criação de uma sociedade justa como era o projeto do iluminismo. Como afirma Benjamin numa das passagens mais conhecidas de Sobre o conceito de história:

Há um quadro de Klee que se chama Agelus Novus. Representa um anjo que parece querer afastar-se de algo que ele encara fixamente. Seus olhos estão escancarados, sua boca dilatada, suas asas abertas. O anjo da história deve ter esse aspecto. Seu rosto está dirigido para o passado. Onde nós vemos uma cadeia de acontecimentos, ele vê uma catástrofe única, que acumula incansavelmente ruína sobre ruína e as dispersa a nossos pés. Ele gostaria de deter-se para acordar os mortos e juntar os fragmentos. Mas uma tempestade sopra do paraíso e prende-se em suas assas com tanta força que ele não pode mais fechálas. Essa tempestade o impele irresistivelmente para o futuro, ao qual ele vira as costas, enquanto o amontoado de ruínas cresce até o céu. Essa tempestade é o que chamamos de progresso (BENJAMIN, 1989, P.226).

Mas esse derrotismo é superado pela esperança quase que ilusória de Benjamin de que dessa 'barbárie' possamos construir algo positivo, como na passagem de Experiência e pobreza citada anteriormente. Pois, afinal de contas como ele afirma que embora o progresso seja uma tempestade, essa tempestade é soprada do paraíso. Nisso me parece que Adorno discorda de Benjamin; não existe esse mesmo otimismo. Para ele, o progresso é mais fácil de ser associado a um gigante que ao despertar saia pisoteando tudo o que encontra pela frente. A possibilidade de saída será encontrada na ilusão ou valor de verdade da arte que pode afirmar uma outra realidade em oposição à existente, rompendo assim com o caráter totalizante do esclarecimento e do progresso.

Conforme afirmado anteriormente, não se pode pensar o progresso sem que se vincule a ele a ideia de humanidade. O projeto de progresso kantiano expresso nas proposições da Ideia de uma história universal de um ponto de vista cosmopolita, também já defendia que o pleno desenvolvimento das disposições e potencialidades do ser humano obedece a leis naturais e universais que são exteriores ao indivíduo e que são determinadas conforme uma finalidade:

Os homens, enquanto indivíduos, e mesmo povos inteiros mal se dão 
conta de que, enquanto perseguem propósitos particulares, cada qual buscando seu próprio proveito e frequentemente uns contra os outros, seguem inadvertidamente, como a um fio condutor, o propósito da natureza, que lhes é desconhecido, e trabalham para sua realização, e, mesmo que conhecessem tal propósito, pouco lhes importaria (KANT, 1986, p.10).

Essas potencialidades só poderão se desenvolver completamente na espécie e não no indivíduo, pois o instrumento necessário para isso, a razão, vai se construindo por meio de tentativas e exercícios, somente aos poucos progride, sendo necessário uma série talvez indefinida de gerações vão que transmitindo às outras seus conhecimentos, para que a espécie possa atingir adequadamente seu propósito.

O antagonismo entre os propósitos dos indivíduos e das sociedades, segundo Kant, é o meio de que a natureza se serve para realizar seu propósito. A 'insociável sociabilidade' dos homens, a busca de projeção, de dominação e a cobiça os levarão a superação da preguiça e a dar os primeiros passos em direção ao esclarecimento, que os levarão da rudeza à cultura. A partir daí, "o maior problema para a espécie humana, cuja solução a natureza a obriga, é alcançar uma sociedade civil que administre o direito" (KANT, 1986, p.14). Sendo que isso só é possível em uma sociedade que permita a máxima liberdade de seus membros, resguardando seus limites de modo que a liberdade de uns possa coexistir com a liberdade dos outros.

Assim uma sociedade na qual a liberdade sob leis exteriores encontrase ligada no mais alto grau a um poder irresistível, ou seja, uma constituição civil perfeitamente justa, deve ser a mais elevada tarefa da natureza para a espécie humana, porque a natureza somente pode alcançar seus outros propósitos relativamente à nossa espécie por meio da solução e cumprimento daquela tarefa (KANT, 1986, p.15).

O problema em se admitir o progresso como algo exterior ao homem de um ponto de vista cosmopolita e não nas esferas de vida particulares, é que "quando a humanidade fica confinada pela totalidade que ela mesma configura, então não existiu, no dizer de Kafka, nenhum progresso, já que, ao mesmo tempo, somente a totalidade permite pensá-lo" (ADORNO, 1995, p. 40). A ideia de um propósito independente da determinação humana seria impensável a não ser que se atribua razão à natureza, o que o tornaria incompatível com a liberdade. Adorno então recorre novamente a Benjamin:

A noção de felicidade das gerações vindouras - sem a qual não é possível falar em progresso - implica inevitavelmente a de redenção. Confirma-se assim a concentração na sobrevivência da espécie: é 
impossível aceitar qualquer progresso como se a humanidade já existisse como tal e, portanto, pudesse progredir. Pelo contrário, o progresso seria a geração da humanidade, perspectiva que se abre pela via da extinção. Segue-se disso, como também ensina Benjamin, que o conceito de história universal é irrecuperável; ele só se manteria na medida em que fosse confiável a ilusão de uma humanidade já existente, internamente harmônica e em movimento ascendente e uniforme (ADORNO, 1995, p. 40).

então aceitar a visão de Heine, para quem o desejo de instaurar aqui na terra instituições políticas e industriais livres que possibilitem a realização da bem aventurança, que segundo os pios só ocorrerá no Céu com o Juízo Final, talvez não passe de uma esperança tola, e sentencia:

Aquela talvez seja uma esperança tão tola quanto esta, e talvez não haja ressurreição da humanidade nem no sentido político-moral, nem no católico-apostólico. Talvez a humanidade esteja destinada à miséria eterna; talvez os povos estejam para todo o sempre condenados a ser esmagados pelos déspotas, explorados por seus cúmplices e zombados por seus lacaios (HEINE, 1991, p. 24).

\section{REFERÊNCIAS}

ADORNO, T. Minima moralia. Tradução: Luis Eduardo Bicca. 2a.edição. Ed. Ática. São Paulo, 1993.

Palavra e sinais: modelos críticos II. Tradução: Maria Helena Ruscel. Editora Vozes. Petrópolis, 1995.

Prismas: crítica cultural e sociedade. Tradução de Augustin Wernet e Jorge Mattos Brito de Almeida. Ed. Ática. São Paulo, 2001.

São Paulo, 1986.

Textos de Theodor W. Adorno. Série Sociologia. Org. Gabriel Cohn. Ed. Ática.

Teoria da semicultura. Tradução: Newton Ramos de Oliveira. In:

Educação \& Sociedade, ano XVII, nº. 56, dezembro/96. Pág.: 388-411.

, Teoria estética. Tradução de Artur Morão. Edições 70. Lisboa - Portugal. 113.

, \& Horkheimer, M. Dialética do esclarecimento. Tradução: Guido

Antonio de Almeida. Jorge Zahar Editores. Rio de janeiro, 1985. Paulo, 1978.

Temas básicos da Sociologia. Tradução: Álvaro Cabral. Editora Cultrix. São 
BENJAMIN, Walter. Magia e técnica, arte e política. Obras escolhidas I. Editora brasiliense. São Paulo, 1989.

Rua de mão única. Obras escolhidas II. Editora brasiliense. São Paulo, 1995.

DOSTOIÉVSKI, F. O crocodilo e notas de inverno sobre impressões do verão. Tradução de Boris Schnaiderman. Editora 34. São Paulo, 2000.

DUARTE, Rodrigo. Adornos: nove ensaios sobre o filósofo frankfurtiano. Belo Horizonte 1997. Ed. UFMG.

Adorno/Horkheimer \& a dialética do esclarecimento. Jorge Zahar Ed. Rio de Janeiro, 2002.

GAGNEBIN, Jeanne Marie. Lembrar, escrever, esquecer. Editora 34. São Paulo, 2006.

HEGEL, G.W.F. A razão na história. Tradução de Beatriz Sidou. Ed. Centauro. São Paulo, 2001.

HEINE, Heinrich. Contribuição à história da religião e filosofia na Alemanha. Ed. Iluminuras. São Paulo, 1991.

HORKHEIMER, M. Eclipse da razão. Tradução: Sebastião Uchoa Leite. Editora Labor. Rio de Janeiro, 1976.

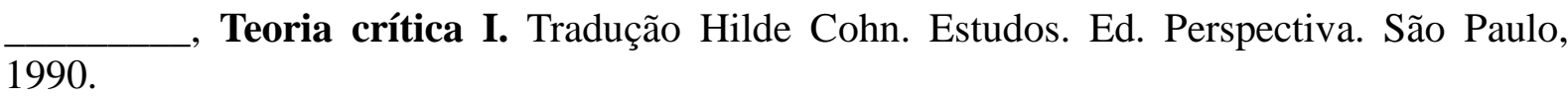
Teoria tradicional e teoria crítica. Tradução: Edgard Afonso Malagodi e Ronaldo Pereira Cunha. In: Coleção Os Pensadores. Editora Nova Cultural, 1983.

KANT, Immanuel. Ideia de uma historia universal de um ponto de vista cosmopolita. Tradução de Rodrigo Naves e Ricardo Terra. Ed. Brasiliense. São Paulo, 1986.

, Textos seletos. Ed. Vozes. Petrópolis, 2005.

Recebido: setembro/2018

Aprovado: novembro/2018 